\title{
DIFFERENCE OF THE PLASTIC STRESS AND RESIDUAL BY HOLLOMAN AND HOOKE EQUATION FOR TWO DIFFERENT STEELS
}

\author{
J. A. MARTINS ${ }^{1}$, E. C. ROMÃO ${ }^{2}$ \\ Desch Canada Ltd $^{1}$, Universidade de São Paulo ${ }^{2}$ \\ estaner23@usp.br ${ }^{1}$
}

Submetido 24/01/2020 - Aceito 11/05/2020

DOI: $10.15628 /$ holos.2020.9449

\section{ABSTRACT}

This paper presents a few applied stresses imposed on two different materials, and the effect of these stresses on material's residual stress. It also shows an equation to calculate residual stress towards the combination between Hooke's and Holloman Laws. In order to calculate the residual stresses, two different materials were chosen, the first is an alloy steel SAE 4340 and a second high strength steel UHB-20C. It is seen that both
\end{abstract}

materials behave similarly, which means the difference between the applied stress and the residual stress is minimal when the applied stress is closer to material tensile strength. However, when the applied stress is closer to the materials yield strength the difference between applied stress and the residual stress is significantly higher.

\section{DIFERENÇA DAS TENSÕES DE DEFORMAÇÕES PLÁSTICA E RESIDUAL PELAS EQUAÇÕES DE HOLLOMAN E HOOKE PARA DOIS DIFERENTES MATERIAIS}

\begin{abstract}
RESUMO
Este artigo apresenta algumas tensões aplicadas em dois diferentes materiais e os efeitos destas tensões na tensão residual do material. Também é apresentada uma equação para calcular a tensão residual através da combinação entre as equações das leis de Hooke e Holloman. Com o objetivo de calcular a tensão residual, dois diferentes materiais foram escolhidos, o primeiro sendo um aço ligado SAE 4340 e um segundo de alta
\end{abstract}

resistência mecânica UHB-20C. Aparentemente os dois materiais apresentaram comportamentos similares, o que significa que a diferença entre a tensão aplicada e a tensão residual é mínima quando a tensão aplicada está próxima a resistência à tração do material. Por outro lado, quando a tensão aplicada está próxima ao seu limite de escoamento a diferença entre a tensão aplicada e a tensão residual é significativamente maior.

Palavras chaves: Deformação plástica, tensão residual, aço ligado, material de alta resistência mecânica, Equação de Hooke, Equação de Holloman. 


\section{INTRODUCTION}

The evolution of the engineering materials and manufacturing processes, from which mechanical parts are generated, have demanded the development of new mathematical models to simulate raw material's internal stresses and strains, generated by external loads, during the manufacturing process of a part. As an example, the process of metal working of metallic materials produces internal stresses called residual stresses, which can result in failure either in raw material during the manufacturing of a part or even when the final product in used. As a matter of fact, failure of parts most likely occurs when the calculations of their residual stress are neglected [1].

As part of residual stress calculation, the elastic stress and elastic strain should be taken into consideration. Elastic stress and elastic deformation can be directly related by Hooke's Law [2] because usually the stress and strain are time independent. It means, upon release of the load, the elastic strain is completely recovered (i.e., the strain returns to zero immediately) [3]. The Hooke's Model is a powerful simple equation which simulates the behaviors of most of materials providing the stress applied and the strain directly related to the stress. The Hooke's Equation is used in most of the linear-elastic software which deal with the design of parts that cannot fail. Failure under linear-elastic perspective means that a part reaches stresses that exceed the material's elastic limit when loaded with an external force or pressure [4-5].

When a material is deformed plastically there is another phase called plastic deformation or non-linear stress-strain. This phase occurs when, in order to change the geometry of materials to produce parts, an external load is applied which exceeds the elastic limit of the material. Therefore, plastic deformation occurs in most of the steps taken along the manufacturing processes. For example processes like forging, drawing, stamping, bending, hydro forming, etc... generate stresses and strains within the materials plastic deformation phase [6]. When the deformation of the material is higher than the elastic limit of the material the internal dislocations in its atomic structure happens, therefore the shear stress acting on the slip plane causes these dislocations to move through the atomic structure. As they move ahead they encounter a few barriers such as solute atoms, metallic particles, grain boundaries and other dislocations, effectively stopping the dislocation until the stress is increased and the dislocation can overcome the obstacle. This atomic movement can be simulated by using an equation called Holloman Equation [7]. Another possibility is when residual stresses are introduced into the material even when the process doesn't change the shape of the part, but it applies pressure enough to add dislocations in atomic structure. Processes like machining, grinding, shot-peening are under this category [8-10].

Residual stress is a topic of great interest in manufacturing of parts and components because the residual stress affects directly the reliability of the final parts in field in terms of life span. This topic is even more relevant when fatigue is one of the topics of main interest for studying. The definition of residual stress, according to Schijve [11], is a stress distribution present in a structure, component, place or sheet, while there is no external load applied.

This paper aims to calculate the residual stress, by combining Hooke's Equation and Holloman Equation, in materials when they are deformed plastically and the external stress is released. For this purpose, Hooke and Holloman laws are combined in order to keep the calculation 
simple but at the same time providing a guideline for engineers in the manufacturing processes. Additionally, two materials with different mechanical properties were chosen to demonstrate the difference between plastic stress and residual stress.

\section{RESIDUAL STRESS CALCULATION}

As described previously, residual stress is a combination of plastic deformation and material elastic recovery. Elastic deformation or elastic recovery, also called spring back modulus [12], is when the material returns to its original shape (geometry) just after the force is applied. Elastic deformation is called elastic recovery when the material is plastically deformed but when the force is released, the material tries to come back to its original shape but it can't due to permanent strain - increased dislocation density. The elastic portion of deformation, called elastic recovery, can be written by using Hooke's Law as follow:

$\sigma_{e r}=E . \varepsilon_{e}$

where $\sigma_{e r}$ as elastic recovery of material, E $(210 \mathrm{GPa})$ as Young Modulus and $\varepsilon_{\mathrm{e}}$ as elastic deformation

When the part passes through a process where its shape is permanently changed it is called plastic deformation, as mentioned, processes like forging, drawing, stamping, bending, etc... promote the change of materials shape. For permanent change - plastic deformation - Holloman Equation is commonly used and it considers that the stress applied on material when it exceeds the material yield strength, as follow:

$\sigma_{p}=K \cdot \varepsilon_{p}^{n}$

where $\sigma_{p}$ is the plastic deformation, called permanent deformation, $\mathrm{K}$ is the strength index or strength coefficient $\varepsilon_{\mathrm{p}}$ as plastic deformation and $n$ as strain hardening index.

In order to determine the residual stress in the material the combination of both equations is necessary. It means that the plastic deformation generates a stress which is close to residual stress but it is not exactly the same because the elastic portion (elastic recovery) of the deformation has to be subtracted from the plastic deformation:

$\sigma_{r} \sim \sigma_{p}$

The $\sigma_{r}$ is the residual stress and $\sigma_{\mathrm{p}}$ is the plastic deformation.

Usually the elastic deformation is calculated by using Hooke's Law, as well as the elastic recovery of the material when it passes through a plastic deformation:

$\varepsilon_{e r}=\frac{\sigma_{a}}{E}$

Where $\varepsilon_{\mathrm{er}}$ is the elastic recovery, $\sigma_{a}$ is the stress applied on component. In regards to plastic deformation the Holloman Equation - Equation (2) - is used and can be manipulated as follow:

$\varepsilon_{p}=\sqrt[n]{\frac{\sigma_{p}}{K}}$ 
In order to determine the residual stress in the material when deformed plastically the elastic portion of material, elastic recovery, has to be subtracted from the total deformation as seen below; $\varepsilon_{N}=\varepsilon_{p}-\varepsilon_{e r}$

$\varepsilon_{N}=\sqrt[n]{\frac{\sigma_{p}}{K}}-\frac{\sigma_{a}}{E}$

Rearranging the Equation (2) placing Equation (7) into it, it leads to:

$\sigma_{R}=K \cdot\left(\left(\sqrt[n]{\frac{\sigma_{p}}{K}}\right)-\frac{\sigma_{a}}{E}\right)^{n}$

Because $\sigma_{a}=\sigma_{p}$ can be assumed as having the same value, the Equation (8) can be rewritten as follow:

$\sigma_{R}=K \cdot\left(\left(\frac{\sigma_{a}}{K}\right)^{\frac{1}{n}}-\frac{\sigma_{a}}{E}\right)^{n}$

\section{Comparison of two different materials}

At the first glance, when comparing differences materials in term of elastic recovery and plastic deformation, which results in residual stress, the values seems to be negligible but they are not. The values are directly related to the type of material considered. In order to elucidate the difference, two materials were chosen, the first alloy steel AISI 4340 [13] and a second high strength steel UHB-20C [14]. Their mechanical properties are demonstrated at Table 1.

Table 1. Mechanical properties of materials SAE 4340 and UHB 20C.

\begin{tabular}{|l|c|c|}
\hline Property / Material & SAE 4340 & UHB 20C \\
\hline Yield strength (MPa) & 475 & 1,600 \\
\hline Tensile strength (MPa) & 744 & 2,300 \\
\hline Strain hardening expoent & 0.15 & 0.0487 \\
\hline Strength index & Not applicable & 2,300 \\
\hline Young Modulus (MPa) & 210,000 & 210,000 \\
\hline
\end{tabular}

For the material AISI 4340 the difference between the residual stress and plastic stress is very small as seen in Figure 1.

The Figure 1 shows the stress difference, which is basically the difference between the stresses applied minus the stress calculated towards Equation 9. For example, when a stress of 500 $\mathrm{MPa}$ is applied the calculated remaining stress (residual stress) is 497.44 , which results a difference between the stress applied (500 MPa) and the residual stress calculated (497.44 MPa) of 2.56 MPa. 


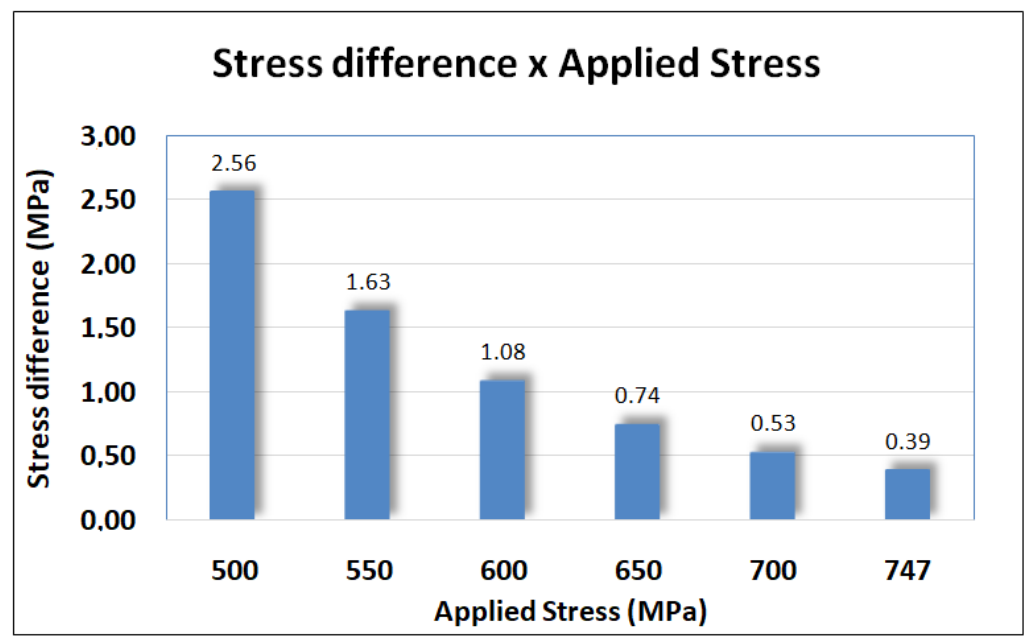

Figure 1. Difference between Stress difference (applied stress minus residual stress) and applied stress for AISI 4340.

As seen, the stress difference decreases with the increase of applied stress in the material. For $500 \mathrm{MPa}$ for example, the stress difference is $2.56 \mathrm{MPa}$, it means $0.51 \%$ of the total applied stress. As the stress increases $50 \%$, rising to $747 \mathrm{MPa}$ the stress difference decreases 6.5 times, which represents a difference of $0.05 \%$.

For the high strength steel, UHB-20C, once the mechanical strength increases the stress difference also increases.

The Figure 2 shows that, for values close to elastic limit the difference between the stress difference and the applied stress are smaller than those close to the material tensile strength.

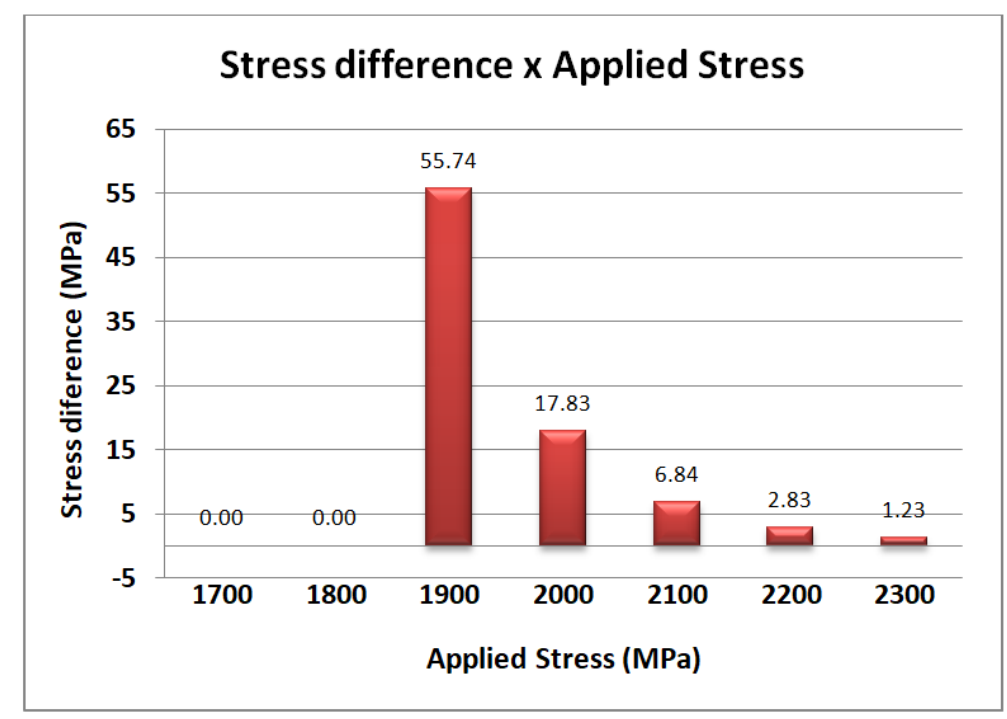

Figure 2. Difference between Stress difference (applied stress minus residual stress) and applied stress for UHB-20C.

The high strength material UHB-20C presents a stress difference of 55.74 MPa for an applied stress of $1.900 \mathrm{MPa}$, which represents around $3 \%$ of it. When the material reaches a very high applied stress of $2.300 \mathrm{MPa}$, which means an increase of $21 \%$ on applied stress, the difference drops to $0.05 \%(1.23 \mathrm{MPa})$. 


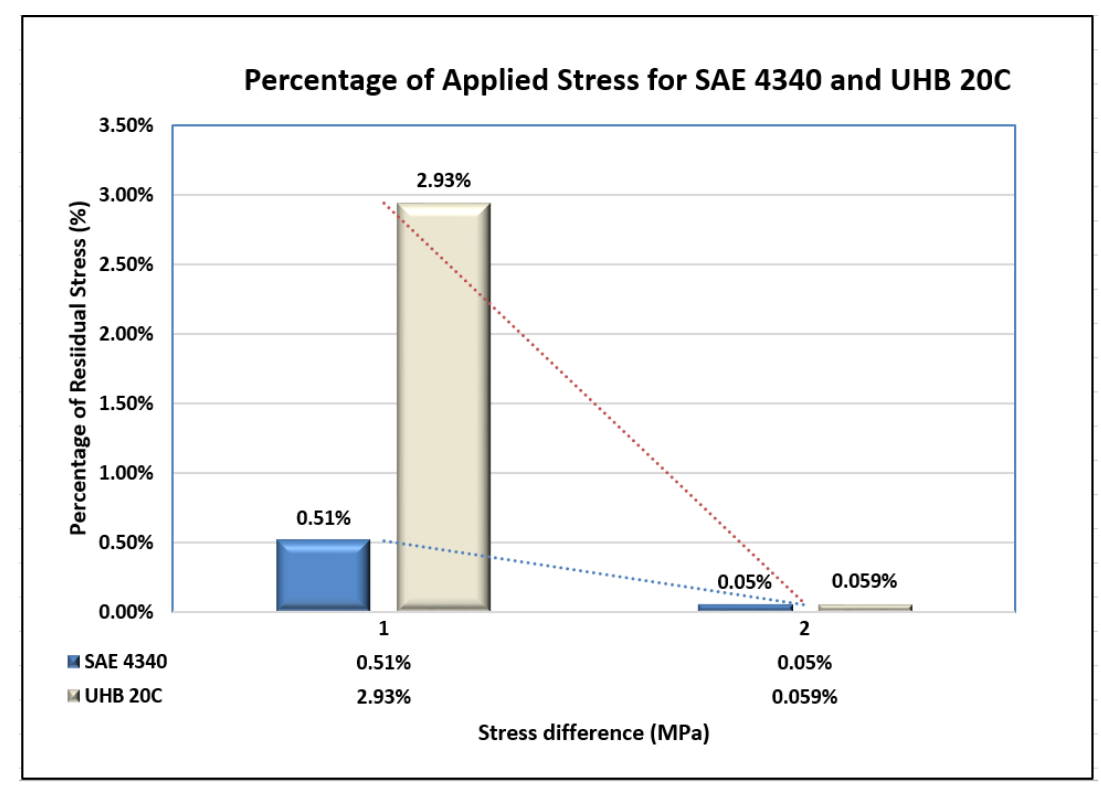

Figure 3. Change in the Stress difference (\%) (applied stress minus residual stress) for two different materials.

The Figure 3 shows that, the material which has higher mechanical strength (UHB 20C) presented a larger decrease in stress difference than the alloy steel SAE 4340. For both materials the differences are larger for stresses close to their tensile yield strength, Stress difference 1 at the graph.

\section{CONCLUSION}

Plastic deformations may be generated during some manufacturing processes, this deformation generates internal stresses in the material, called residual stress. Whether or not residual stress is considered during designing of product and processes, parts can last as expected or fail (fracture). The calculations of stress differences for two different materials (AISI 4340 and UHB-20C) showed that, there is a change in the stress difference (delta $\sigma$ ) between both materials. Nevertheless, both materials presented the same behavior when the stresses were closer to their yield strength, higher values, and same trend when the applied stress is closer to tensile strength, minimal values. In fact, the stress difference close to the tensile strength is minimal and can be negligible by engineers, on the other hand, it is not true for stresses close to yield strength. However, if the applied stress is close to the yield strength of material it is highly recommendable to use safety factor in favor of a safer design. Finally, the residual stress is dependent of the mechanical strength of the material under consideration, the process applied to manufacture the part, mainly if the geometry is changed by plastic deformation, and external loads (stresses) on parts when in use.

\section{REFERENCES}

Martins, J. A., Cardoso, L. P., Fraymann, J. A., Button, S. T. (2006). Analyses of residual stresses on stamped valves by $\mathrm{X}$-ray diffraction and finite elements method. Journal of materials processing technology, vol. 179 , no 1-3, pp. 30-35. 
Rychlewski, J. (1984). On Hooke's law. Journal of Applied Mathematics and Mechanics, vol. 48, no 3, pp. 303314.

Chen, Y., Liao, X. (2016). Chapter Four - Mechanical Behaviors of Semiconductor Nanowires. Semiconductors and Semimetals, Vol. 94, 1 st Edition, pp. 109-158.

Roylance, D. (2008). Mechanical Properties of Materials, MIT. Access: http://web.mit.edu/course/3/3.225/book.pdf

Hertzberg, R., Vinci, R. P., Hertzberg, J. L. (2012). Deformation and Fracture Mechanics of Engineering Materials, New Year: Wiley, 5th Edition, 784 pgs.

Clift S. E., Hartley, P., Sturgess, C. E. N., Rowe, G. W. (1990). Fracture prediction in plastic deformation processes. International Journal of Mechanical Sciences, vol. 32, no 1, pp. 1-17.

Meier, M. (2004). Plastic Deformation and the onset of tensile instability. University of California. Access http://www.kstreetstudio.com/science/experiments/files/Tensilelnstability.pdf

Brinksmeier, E., Cammett, J. T., König, W., Leskovar, P. J. and Peters, H. K. (1982). Tönshoff, residual stresses - measurement and causes in machining processes. Annals of the CIRP, Vol. 31, No. 2, pp. 491-510.

Hamdi, H., Zahouani, H., Bergheau, J. M. (2004). Residual stresses computation in a grinding process. Journal of Materials Processing Technology, vol. 147, no 3, pp. 277-285.

Meguida, S. A., Shagala, G., Stranarta, J. C., Dalyb, J. (1999). Three-dimensional dynamic finite element analysis of shot-peening induced residual stresses. Finite Element in Analysis and Design, Vol. 31, no 3, pp. 179-191.

Residual Stress. In: Schijve J. (eds) . (2009). Fatigue of Structures and Materials. Springer, Dordrecht, pp. 89-104.

Luo, L., Ghosh, A. K. (2003). Elastic and Inelastic Recovery After Plastic Deformation of DQSK Steel Sheet. Journal of Engineering Materials and Technology, Vol. 125, no 3, p. 237-246.

Callister Jr, W. D., Rethwisch. D. G. (2012). Fundamentals of Materials Science and Engineering, John Wiley \& Sons.

Nadar, V. S. (2014). Fatigue testing of scratched flapper valve steel. Degree project for master of science in engineering, mechanical engineering. https://pdfs.semanticscholar.org/ad2d/d4f81c76e875a79a379fb80a823815bb8a2a.pdf 